\title{
Assessing biological invasions in protected areas after 30 years: Revisiting nature reserves targeted by the 1980s SCOPE programme
}

\author{
Ross T. Shackleton ${ }^{\mathrm{a}, \mathrm{b}, *}$, Llewellyn C. Foxcroft ${ }^{\mathrm{c}, \mathrm{b}}$, Petr Pyšek ${ }^{\mathrm{d}, \mathrm{e}, \mathrm{b}}$, Louisa E. Wood ${ }^{\mathrm{f}, \mathrm{g}}$, \\ David M. Richardson ${ }^{\mathrm{b}}$ \\ ${ }^{a}$ Institute of Geography and Sustainability, University of Lausanne, 1015 Lausanne, Switzerland \\ ${ }^{\mathrm{b}}$ Centre for Invasion Biology, Department of Botany and Zoology, Stellenbosch University, Matieland 7602, South Africa \\ ${ }^{c}$ Scientific Services, South African National Parks, Kruger National Park, Private Bag X402, Skukuza 1350, South Africa \\ ${ }^{\mathrm{d}}$ Institute of Botany, Department of Invasion Ecology, Czech Academy of Sciences, CZ-252 43 Průhonice, Czech Republic \\ ${ }^{\mathrm{e}}$ Department of Ecology, Faculty of Science, Charles University, Viničná 7, CZ-128 44 Prague, Czech Republic \\ ${ }^{\mathrm{f}}$ Department of Botany and Zoology, Stellenbosch University, Matieland 7602, South Africa \\ ${ }^{\mathrm{g}}$ Centre for Environment, Fisheries and Aquaculture Science, Weymouth, Dorset, UK
}

\section{A R T I C L E I N F O}

\section{Keywords:}

Biodiversity

Conservation

Invasive alien species

Management

Global environmental change

Impact

Nature reserves

National parks

SCOPE

\begin{abstract}
A B S T R A C T
Invasive alien species pose a major threat to biodiversity and natural ecosystems globally and negatively affect conservation efforts in protected areas. They can negatively alter biodiversity and ecological regimes and are a financial burden. Because of their negative impacts, it is important to better understand the threat and management of invasive alien species in protected areas (PAs) globally, and to know how these factors have changed over time. We give an update and compare how the threat and management of invasive species has changed in 21 PAs that were analysed as part of the international SCOPE programme on biological invasions in the mid1980s. Of all the taxa analysed, invasive plants pose the greatest continued threat, and their numbers have increased in $48 \%$ of the PAs. Conversely, mammal invasions now represent less of a threat due to effective management in many PAs; $48 \%$ of PAs show a decrease in listed invasive alien mammal taxa. Invasions of amphibians, reptiles, birds and fish have remained stable over the three decades; around half of the PAs show no change for these taxa. Managers of most PAs consider the threat of invasions to be increasing, despite many (55\%) PAs having sustained long-term management programmes and $45 \%$ having implemented additional ad hoc approaches. We draw on lessons from this analysis to support the future management of biological invasions in conservation areas. In particular, better monitoring and collation of data is needed, followed by increased preventative measures and the promotion of biological control for widespread species.
\end{abstract}

\section{Introduction}

Biological invasions are a major driver of global environmental change in the Anthropocene. Invasive alien species (IAS) are those that have been moved by humans accidentally and/or purposefully into new environments, where they survive, naturalise and spread over large areas, often inducing negative social-ecological impacts (see Richardson et al., 2000 for detailed definitions). IAS threaten ecosystem services, human well-being, and biodiversity (Pejchar and Mooney, 2009; Butchart et al., 2010; Foxcroft et al., 2017a, 2017b; Vilà and Hulme, 2017; Shackleton et al., 2019a). They are a leading cause of native species extinctions and population declines, and alter community structure and ecosystem function, resulting in biodiversity loss globally (Clavero and García-Berthou, 2005; Hejda et al., 2009;
Downey and Richardson, 2016; Pyšek et al., 2017). Invasive species negatively affect biodiversity through a range of mechanisms including predation (Blackburn et al., 2004), competition for limited resources (Vilà and Weiner, 2004), alteration to genetic flows and make up (Huxel, 1999), and alterations to natural ecological cycles and regimes (Gaertner et al., 2014). These factors all hinder effective conservation initiatives.

Due to rapid global change and environmental degradation, protected areas (PAs) are crucial for preserving biodiversity and ecosystem function (Conroy et al., 2011; Foxcroft et al., 2017a, 2017b). This makes monitoring and understanding conservation threats important to allow for the implementation of effective legislative measures and policy to guide management strategies (Mačić et al., 2018), and to reach Aichi Target 9 goals under the Convention on Biological

\footnotetext{
* Corresponding author at: Institute of Geography and Sustainability, University of Lausanne, 1015 Lausanne, Switzerland.

E-mail address: rtshackleton@gmail.com (R.T. Shackleton).
} 
Diversity. Despite this, long-term monitoring is lacking and assessments are urgently needed to analyse trends, successes and failures, and guide management into the future.

In the mid-1980s a working group on biological invasions, part of the international SCOPE programme (Scientific Committee on Problems of the Environment), explored IAS in nature reserves (hereafter PAs) globally. This work resulted in the publication of a special issue of Biological Conservation (Usher et al., 1988) which included papers on IAS in arid (Loope et al., 1988), island (Brockie et al., 1988), Mediterranean (Macdonald et al., 1988) and savanna PAs (Macdonald and Frame, 1988), and a synthesis article summarizing the results and evaluating the threats from biological invasions to PAs worldwide (Usher, 1998). The SCOPE programme was a trigger for the rapid growth in the field now known as invasion science (Mooney et al., 2005; Simberloff, 2011; Richardson, 2011). The SCOPE studies on invasions in PAs focussed on 24 conservation areas dispersed across six continents and within different biogeographical, social and ecological settings. The special issue was influential in highlighting the threat of IAS for conservation and placing the need to control IAS on the agenda for policy and management. The SCOPE programme (and also its invasive species working group) focussed on three key questions: 1) what make some species invasive; 2 ) what properties make areas more prone to, or resistant to, invasion; and, 3) how should management systems be developed? In answering these questions, nature reserves were selected as benchmarks for undisturbed sites, as it was assumed that IAS did not invade undisturbed sites.

In this paper we collated data for the same PAs that were studied during the SCOPE programme and assess how biological invasions and their management have changed over the last $\sim 30$ years. We gave special attention to the threat that IAS impose and to assessing current and past management efforts that are in place to mitigate their impacts.

\section{Methods}

The original SCOPE studies compiled lists of invasive species for each of 24 PAs chosen to provide a representative sample of the world's main biogeographical and ecological settings (Table 1; Fig. 1). PAs in arid and semi-arid land (desert), Mediterranean areas, tropical savannas and dry woodlands and islands were chosen to cover a number of different biomes. Total numbers of invasive species in the different taxonomic groups were made available for each of the 24 PAs in the papers published in the Biological Conservation special issue. However, the checklists of actual species in each reserve were not included in the publications and have been lost over time (I.A.W. Macdonald; pers. comm.). We could therefore only extract the lists of species that were specifically mentioned as occurring in the respective reserves in the special issue articles. We extracted information on plants and animals (including amphibians, birds, freshwater fish, mammals and reptiles). Although some data were presented on microorganisms, insects and invertebrates, these were not very accurate or comprehensive (mainly estimates) and were only available for a few PAs. We therefore chose not to include them in this study. From the publications, we also recorded PAs that had management initiatives in place in the 1980s.

We used a survey approach to collect data from the same 24 PAs and to update the information for 2018 or as close as possible (see Supplementary Material File 1). We sent a questionnaire via email to park managers or researchers with experience in the different PAs to request data (see Supplementary Material, File 5). Searching for relevant key informants and collation of the data was done between April 2016 and September 2018. We were unable to obtain responses from three of the original protected areas: Death Valley National Monument, Salvages Islands and La Campana (Fig. 1). Also, no further work, management and monitoring has been done in Skeleton Coast NP in Namibia (H. Kolberg: pers. comm.), so with the help of local experts we made assumptions on the invasion status now as compared to the 1980s. Comprehensive responses received for 21 PAs were included in the study.

We asked each respondent to provide information on the total number of alien and invasive species found in the park (following the definition of Richardson et al., 2000), covering six different taxonomic groups (plants, freshwater fish, amphibians, reptiles, birds and mammals). We also asked respondents to list up to 10 of the currently most serious and threatening invasive species regardless of the taxonomic group, and up to 10 potentially threatening species for each of these groups.

We also collated information about past and current management. Respondents were provided with the 1980s species list extracted from the publications and were asked about the current status of these species. A number of questions relating to monitoring and management implementation were included (see Appendix 1 for the questionnaire). For one PA, reserve boundaries have changed substantially. The Cape of Good Hope Nature Reserve (hereafter referred to as Cape of Good Hope) that was surveyed in the 1980s is now part of the much larger Table Mountain National Park (TMNP). We consulted local experts to ensure that we only included species from the Cape of Good Hope section of TMNP for comparison.

For comparing the number of species listed between the two monitoring periods we used paired sample $t$-tests. To test categorical changes between the two periods (increase, decrease, same, unknown) and the perceptions of changes in threat levels by mangers for different taxa over time we used chi-squared tests. As some assumptions did hold, we used the likelihood ratio values based on these chi-squared tests rather than $\chi^{2}$ values.

\section{Results}

\subsubsection{Changes in numbers of IAS between the 1980s and 2018}

In more than half of the case-study PAs (54\%), the total number of alien species listed has increased, while overall decreases since the 1980 s were evident in $20 \%$ of PAs. In terms of invasive alien species listed, more PAs (42\%) showed a decrease than an overall increase (32\%); while trends for the remainder of PAs were uncertain. Large increases in alien and invasive species listed were recorded in Galápagos, Kings Park, Kruger, Haleakalā, Serengeti-Ngorongoro, Canyonlands and Arches and Organ Pipe Cactus National Monument (see Supplementary Material File 2, for detailed summaries for each PA). Large decreases in species listed are evident for HluhluweiMfolozi, Aldabra and Cape of Good Hope. Large increases were generally attributable to more plant taxa being listed as alien or invasive, with a few exceptions for other taxa (discussed below).

There were significant $(p=0.001)$ differences in the changes in numbers of invasive species among different taxa from 1980s to 2018 (Fig. 2). Plants showed the biggest changes (Table 1). About half (48\%) of the PAs showed an increased number of invasive alien plants, while about a quarter $(26 \%)$ showed a decrease. Major increases in the number of listed plant taxa are evident for Serengeti-Ngorongoro, Canyonlands and Arches, Galápagos and Kings Park (see Supplementary Material, File 2 for detailed descriptions for each PA) which represent PAs in many different social-ecological contexts. Conversely, large declines were evident for Hluhluwe-iMfolozi and Kakadu, while other areas showed small changes (Table 1). Mammals showed the biggest declines in the number of invasive species listed, with $48 \%$ of the PAs having fewer invasive mammals listed in 2018 compared to the 1980s, while $21 \%$ of PAs showed increases. The greatest increase in mammals was seen in the Galápagos, Sequoia and Kings Canyon and Canyonlands and Arches, while major decreases are evident for Hluhluwe-iMfolozi, Channel Islands and the Cape of Good Hope (Table 1). A third of PAs (37\%) showed a drop in the number of bird species listed as invasive, while $16 \%$ showed increases in invasive birds. For fish, amphibians and reptiles, most PAs have similar numbers of invasive species listed at 
Table 1

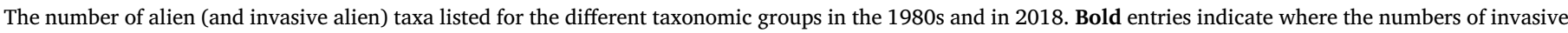

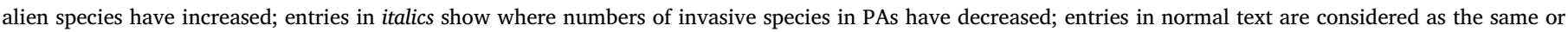

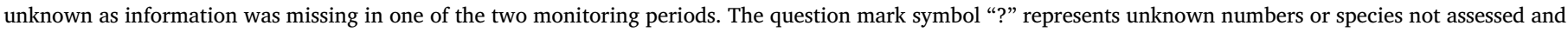
the symbol "0" means no species recorded.

\begin{tabular}{|c|c|c|c|c|c|c|c|c|c|c|c|c|}
\hline \multirow[t]{2}{*}{$\mathrm{PA}$} & \multicolumn{2}{|l|}{ Plants } & \multicolumn{2}{|l|}{ Fish } & \multicolumn{2}{|c|}{ Amphibians } & \multicolumn{2}{|c|}{ Reptiles } & \multicolumn{2}{|l|}{ Birds } & \multicolumn{2}{|c|}{ Mammals } \\
\hline & 1988 & 2018 & 1988 & 2018 & 1988 & 2018 & 1988 & 2018 & 1988 & 2018 & 1988 & 2018 \\
\hline \multicolumn{13}{|c|}{ Savanna } \\
\hline Serengeti \& Ngorongoro & $12(12)$ & $245(23)$ & $1(1)$ & $1(1)$ & 0 & 0 & 0 & 0 & 0 & 0 & $1(1)$ & 2(2) \\
\hline Kruger & $156(113)$ & $367(118)$ & 0 & $3(1)$ & 0 & 0 & $1(1)$ & 0 & $6(1)$ & $3(1)$ & $4(3)$ & $3(1)$ \\
\hline Hluhluwe-iMfolozi & $74(71)$ & $55(17)$ & 0 & 0 & 0 & 0 & $1(1)$ & 0 & $6(9)$ & $2(2)$ & $9(4)$ & $2(2)$ \\
\hline Balura & $?(33)$ & $?(24)$ & $?$ & & $?$ & 0 & $?$ & 0 & 0 & 0 & $2(2)$ & $3(3)$ \\
\hline Kakadu & $?(67)$ & $49(49)$ & $?$ & 0 & 0 & 1(1) & 0 & $2(0)$ & 0 & 0 & $?(5)$ & $7(7)$ \\
\hline \multicolumn{13}{|c|}{ Desert } \\
\hline Canyonlands \& Arches & $55(48)$ & $119(113)$ & $6(6)$ & $24(24)$ & 0 & 1(1) & 0 & 0 & 0 & $5(0)$ & $1(1)$ & $1(0)$ \\
\hline Organ Pipe Cactus & $36(33)$ & $66(43)$ & 0 & 0 & 0 & 0 & 0 & 0 & $3(3)$ & $4(0)$ & $1(1)$ & $1(0)$ \\
\hline \multicolumn{13}{|c|}{ Islands } \\
\hline Channel & $80(78)$ & $80(78)$ & 0 & 0 & 0 & 0 & 0 & 0 & $1(1)$ & $7(7)$ & $6(6)$ & 1(1) \\
\hline Campbell & $77(?)$ & $83(13)$ & 0 & 0 & 0 & 0 & 0 & 0 & $10(?)$ & $6(0)$ & $3(?)$ & 0 \\
\hline Isle of Rum & $62(?)$ & $60(2)$ & 0 & 0 & 0 & 0 & 0 & 0 & $10(?)$ & 0 & $6(?)$ & $5(3)$ \\
\hline Haleakalā & $315(?)$ & $427(420)$ & 0 & 0 & $5(?)$ & 0 & 0 & 0 & $17(?)$ & 0 & $9(?)$ & $5(3)$ \\
\hline Aldabra & $87(?)$ & $80(2)$ & $?$ & 0 & $?$ & 0 & 0 & 0 & $1(1)$ & 0 & $4(?)$ & $2(2)$ \\
\hline Galápagos & $240(?)$ & $810(143)$ & 0 & 0 & 0 & $1(1)$ & 0 & $4(4)$ & $3(?)$ & $8(2)$ & $11(?)$ & $12(10)$ \\
\hline \multicolumn{13}{|c|}{ Mediterranean } \\
\hline Jasper Ridge & $?(175)$ & $182(82)$ & $6(6)$ & $8(4)$ & $1(1)$ & $1(1)$ & 0 & $1(0)$ & $4(1)$ & $3(3)$ & $5(3)$ & $5(5)$ \\
\hline Sequoia \& Kings Canyon & $89(89)$ & $219(78)$ & $3(3)$ & $9(8)$ & $1(1)$ & $1(1)$ & 0 & 0 & $5(5)$ & $11(2)$ & $7(3)$ & $5(1)$ \\
\hline Pinnacles & $79(77)$ & $126(75)$ & $1(1)$ & $1(1)$ & 0 & 0 & 0 & 0 & $5(4)$ & $5(5)$ & $5(4)$ & $4(4)$ \\
\hline Kings Park & $102(102)$ & $341(254)$ & $?$ & 0 & 0 & 0 & $?$ & 0 & $6(6)$ & $8(3)$ & $5(5)$ & $6(4)$ \\
\hline Myall Lakes & $42(42)$ & ? & $?$ & $2(2)$ & 0 & 0 & $?$ & 0 & $7(3)$ & $5(0)$ & $7(7)$ & 9(9) \\
\hline Cape of Good Hope & $80(73)$ & $73(73)$ & $1(1)$ & 0 & $1(1)$ & $1(1)$ & $1(1)$ & 0 & $8(4)$ & 0 & $10(8)$ & $2(2)$ \\
\hline $\begin{array}{l}\text { Statistics (paired t-test) for alien and (invasive) species } \\
\text { listed }\end{array}$ & & $P=0.019(\mathrm{NS})$ & & NS (NS) & & NS (NS) & & NS (NS) & & NS (NS) & & NS (NS) \\
\hline
\end{tabular}

both times, although there are exceptions. In Canyonlands and Arches the number of listed invasive fish increased dramatically from 6 to 24 . Conversely, in Jasper Ridge and Sequoia and Kings Canyon the number of listed fish taxa dropped considerably (Table 1).

\subsubsection{Current and potential invasive alien species}

In total 137 different taxa were identified as current major threats, and 112 were considered to be potential threats (see Supplementary material, Files 2 and 3) (developed from "top 10 lists" of species identified by managers (see Supplementary Material, File 5)). Plants had the highest numbers of taxa associated with current (95) and potential (77) threats. For mammals, 19 taxa were mentioned as posing current major threats, while 11 taxa were identified as a potential threat. Only one reptile species in one PA (Trachemys scripta subsp. elegans in Jasper) was identified as a current threat while nine species were listed as potential threats. Two different amphibian species were listed as current threats, and four different species were listed as potential threats. For freshwater fish, 20 species were listed as current

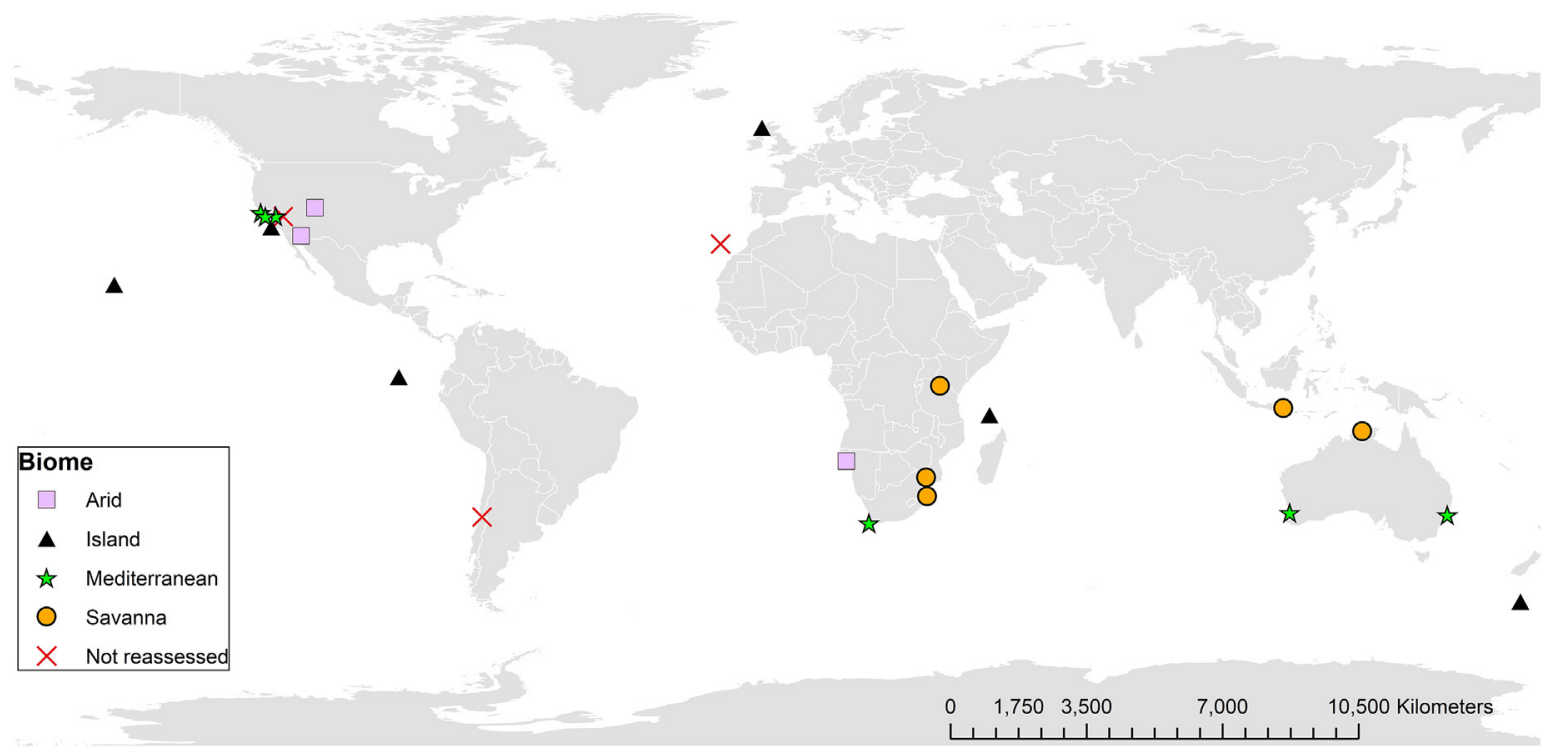

Fig. 1. Locations of the 24-case study protected areas studied in the 1980s and reassessed in 2018, including the three PAs for which information could not be recollected (marked with an $\mathrm{x}$ ). *For more details see Table 1 and File one of the Supplementary material. 


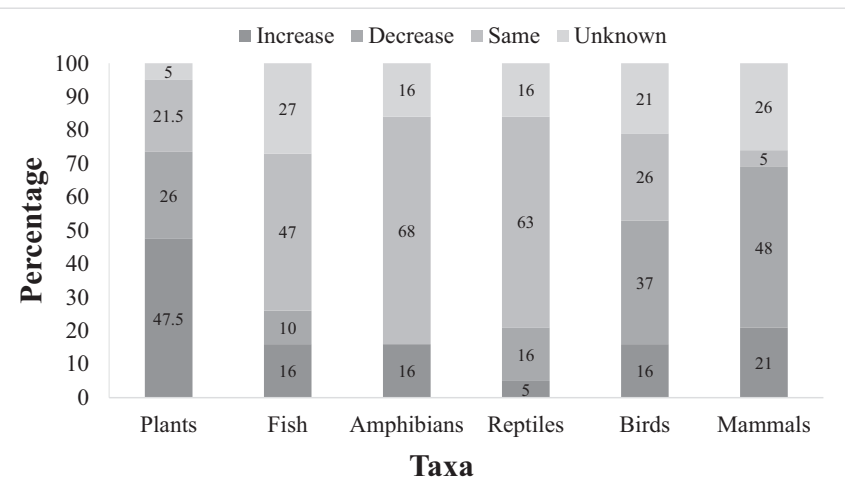

Fig. 2. Changes in the number of different taxa listed as invasive between 1980s and 2018 in 21 protected areas across the globe. The proportion of change between different taxa were significantly different (LH-ratio $=46.078$, $p=0.001$ ).

threats, while 11 were listed as potential threats (Supplementary Material Files 2 and 3).

In general, few species deemed major threats were found in multiple PAs, but of these, mammals were the most common taxa. Felis catus was listed as a major threat in 10 PAs, followed by Rattus rattus (six), Sus scrofa (four), and Bos taurus and Equus asinus (three in each) with the rest being found in two PAs (Table 2). For plants, Lantana camara was listed as a major threat in seven PAs, followed by Centaurea solstitialis, Parthenium hysterophorus and Chromolaena odorata, (listed in three) with the remainder found in two PAs (Table 2). Some genera like Acacia, Asparagus, Bromus, Opuntia, Pennisetum and Pistia were also common, but with different species listed in different PAs. Lithobates catesbeianus was the only amphibian listed in more than one PA, and the only bird was Acridotheres tristis. Two fish (Lepomis cyanellus and Micropterus salmoides) were listed as major threats in two PAs.

In terms of potential future threats, plants were more commonly listed than other taxa (Table 3). Arundo donax, C. odorata and Cryptostegia grandifolia were listed in three PAs, with the remainder listed in two. The reptile Hemidactylus frenatus was mentioned in three PAs. All other species in Table 3 were listed in two PAs. No amphibians were listed as posing a potential threat in two or more PAs.

\subsubsection{Management of invasive species}

3.1.3.1. General management trends. In the 1980 s $75 \%$ of case-study PAs had some form of management in place. Since that time management has taken place continuously or occasionally in $95 \%$ of PAs, with only one park (Skeleton Coast) having had no management interventions over the last 30 years (Table 4, Supplementary Material Files 2 and 4). Of the PAs that have been managing IAS, management

Table 2

A list of species found in two or more protected areas, which have been indicated as a major threat to protected areas in order of most common, based on a list of a maximum of 10 species for each taxon (in many cases fewer).

\begin{tabular}{llc}
\hline Plants & Mammals & Other taxa \\
\hline Lantana camara & Felis catus & Fish \\
Parthenium hysterophorus & Rattus rattus & Lepomis cyanellus \\
Genista monspessulana & Sus scrofa & Micropterus salmoides \\
Dittrichia graveolens & Bos taurus & Amphibians \\
Centaurea solstitialis & Equus caballus & Lithobates catesbeianus \\
Arundo donax & Bubalus bubalis & Birds \\
Opuntia stricta & Canis lupus familiaris & Acridotheres tristis \\
Leucaena leucocephala & Equus asinus & \\
Hirschfeldia incana & Mus musculus & \\
Carduus pycnocephalus & Vulpes vulpe & \\
Arundo donax & & \\
Bromus tectorum & & \\
\hline
\end{tabular}

Table 3

Species that may pose potential major future threats in more than one protected area. This list is based on a summation of lists for the 21 PAs for which a maximum of 10 species could be mentioned (in many cases fewer were listed).

\begin{tabular}{lc}
\hline Plants & Other taxa \\
\hline Arundo donax & Fish \\
Pennisetum setaceum & Gambusia affinis \\
Chromolaena odorata & Reptiles \\
Cryptostegia grandiflora & Hemidactylus frenatus \\
Lantana camara & Birds \\
Lepidium latifolium & Acridotheres tristis \\
Parthenium hysterophorus & Columba livia \\
Rubus armeniacus & Streptopelia decaocto \\
Taeniatherum caput-medusae & Sturnus vulgaris \\
Delairea odorata & Mammals \\
& Rattus norvegicus \\
& Sus scrofa \\
\hline
\end{tabular}

Table 4

A summary of management interventions in the case study protected areas (see Supplementary Material Files 2 and 4 for further details).

\begin{tabular}{ll}
\hline Managed related activities & $\begin{array}{l}\text { Percentage (\%) of } \\
\text { PAs }\end{array}$ \\
\hline $\begin{array}{l}\text { Regular/continuous management programmes to remove } \\
\text { IAS (every year for the last 20 years or more) }\end{array}$ & 55 \\
Regular monitoring (every 5 years or less) & 60 \\
Preventative control & 70 \\
Early Detection Rapid Response (EDRR) programmes & 70 \\
Eradication campaigns & 80 \\
Containment strategies & 75 \\
Biological control use & 65 \\
Formalized management plan & 65 \\
Have an annual management budget & 75 \\
\hline
\end{tabular}

has been continuous since the 1980s in 50\%, and one PA had occasional management up until 1996 when it became a continuous operation. For $40 \%$ of the PAs, management has taken place on an ad hoc or short term basis, in most cases due to sporadic funding availability (Table 4). Sixty percent of the PAs currently have regular monitoring programmes in place for listing invasive species; in most cases, this is done annually or continually, but some do this formally every $2-5$ years to update species lists. More than half of PAs (65\%) that do monitor species presently also try to assess and monitor some invasions spatially, and a few attempt to monitor impacts.

Seventy percent of PAs have preventative measures in place; such measures generally include sterilisation of equipment, monitoring vectors, putting up containment fencing, and using education and awareness raising programmes to help prevent visitors and those living nearby to the PAs from introducing or spreading invasive species. Some PAs also have less common prevention programmes, including using special feeds for horses. Preventative measures are particularly common on island PAs where they are easier to implement as compared to mainland PAs. Similarly, $70 \%$ of PAs have early-detection, rapidresponse (EDRR) programmes in place for specific species or groups of taxa.

Seventy-five percent of PAs have attempted eradication/extirpation of one or more IAS at some point, and $70 \%$ reported ongoing attempts in 2018. Of these PAs, 71\%, have had successful eradications/extirpation of one or more species (Table 5). However, the majority of PAs $(78 \%)$ that have attempted eradication also have at least one or more failed attempt. Successes have been reported for Aldabra where, thanks to a large number of successful eradication campaigns, fewer problematic invasive species are now present as compared to 30 years ago. Such successes have been aided by strong biosecurity practices, but are also due to very low human visitation levels (Supplementary material 
Table 5

Species that have been successfully eradicated/extirpated (those specifically mentioned in the 1980 s report as a threat are marked *).

\begin{tabular}{|c|c|}
\hline Protected area & Species successfully eradicated/extirpated \\
\hline \multicolumn{2}{|l|}{ Savanna } \\
\hline Kruger & $\begin{array}{l}\text { Plants: Hylocereus undatus, Harrisia martini, Eucalyptus } \\
\text { spp., Acacia decurrens }\end{array}$ \\
\hline Kakadu & Plants: Eichhornia crassipes*, Parkinsonia aculeata \\
\hline \multicolumn{2}{|l|}{ Desert } \\
\hline $\begin{array}{l}\text { Canyonlands and } \\
\text { Arches NP }\end{array}$ & $\begin{array}{l}\text { Plants: Lythrum salicaria, Centaurea diffusa, Centaurea } \\
\text { maculosa }\end{array}$ \\
\hline Organ Pipe & Plants: Nicotiana glauca*, Centaurea melitensis \\
\hline \multicolumn{2}{|l|}{ Islands } \\
\hline \multirow[t]{2}{*}{ Channel island } & Plants: Centaurea solstitialis (some islands) \\
\hline & $\begin{array}{l}\text { Mammals: Rattus rattus (some islands), Sus scrofa, Canis } \\
\text { familiaris, Ovis ovis, Bos taurus, Cervus canadensis, } \\
\text { Oryctolagus cuniculus, Odocoileus hemionus } \\
\text { Birds: Meleagris gallopavo }\end{array}$ \\
\hline Campbell & $\begin{array}{l}\text { Mammals: Rattus norvegicus*, Felis catus* (died out with } \\
\text { not much intervention), Ovis aries, Bos taurus }\end{array}$ \\
\hline Haleakalā & Plants: Verbascum thapsus, Morella faya, Erica lusitanica \\
\hline \multirow[t]{3}{*}{ Aldabra } & Plants: Agave sisalana \\
\hline & Mammals: Capra aegagrus*, Capra aegagrus \\
\hline & Birds: Pycnonotus jocosus, Foudia madagascariensis \\
\hline Galápagos & $\begin{array}{l}\text { Plants: Pueraria phaseoloides var. javanica, Opuntia sp. } \\
\text { Birds: Columba livia } \\
\text { Fish: Oreochromis niloticus }\end{array}$ \\
\hline \multicolumn{2}{|l|}{ Mediterranean } \\
\hline Jasper Ridge & $\begin{array}{l}\text { Plants: Ailanthus altissima*, Galium murale*, Cortaderia } \\
\text { selloana* }\end{array}$ \\
\hline \multirow[t]{2}{*}{ Pinnacles } & $\begin{array}{l}\text { Plants: Ailanthus altissima*, Tribulus terrestris, Salsola } \\
\text { tragus }\end{array}$ \\
\hline & $\begin{array}{l}\text { Mammals: Sus scrofa (internal fenced part), Capra hircus } \\
\text { Fish: Lepomis cyanellus/macrochirus }\end{array}$ \\
\hline Kings Park & Mammals: Felis catus*, Funambulus palmarum \\
\hline Myall Lakes & Plants: Salvinia adnata \\
\hline Cape of Good Hope & Plants: Hakea spp. \\
\hline
\end{tabular}

Files 2 and 4). Similarly, the threat of invasive species on Campbell Island is relatively stable despite very few control and eradication attempts, but the island is very isolated and has few visitors. The situation is very different in Galápagos, which has had a number of successful eradications, but where increasing tourism and human settlement mean that there have been many more introductions and more failed eradication attempts.

Containment using mechanical and chemical control has been successful for some species, for example, in Haleakalā National Park, and the potential impact of many species has been reduced. Similarly, the invasion of $C$. odorata in Hluhluwe-iMfolozi has been well contained. One or more biological control agents (the use of tested host-specific natural enemies of particular invasive species) are present in $65 \%$ of PAs, although outcomes are mixed, ranging from highly successful to failed (see detailed summaries for case studies in the Supplementary Maternal, File 2). For example, widespread species that have had some of the best management outcomes in Kruger National Park since the 1980s are those under biological control. These include; Opuntia stricta (agents: Cactoblastis cactorum, Dactylopius opuntiae), Sesbania punicea (agents: Rhyssomatus marginatus, Trichapion lativentre), and the water weeds Azolla cristata (agent: Stenopelmus rufinasus), Pistia stratiotes (agent: Neohydronomus affinis) and Salvinia adnata (previously, molesta) (agents: Cyrtobagous salviniae, Neodiplogrammus quadrivattatus) and partial control of Eichhornia crassipes (agents: Cercospora rodmanii, Eccritotarsus catarinensis, Neochetina bruchi, Neochetina eichhorniae, Niphograpta albiguttalis, Orthogalumna terebrantis). These species no longer pose major threats and need less input from other, often costly, control methods (see Supplementary Martial, File 2). Many other plants have been successfully controlled and invasions contained using biological control in other case-study PAs too, for example Australian Acacia species in the Cape of Good Hope, Tamarix ramosissima in a few
PAs in the USA and Rodolia cardinalis in Galápagos. However, biological control is sometimes ineffective for some invasive species, as agents fail to establish in the region or result in negligible population declines and/or impact reduction - for example, Lantana camara in Kruger National Park and S. adnata in Kakadu (see Supplementary Martial, File 2 for more examples).

More than a third of PAs (35\%) do not have and have never had formal management plans (Table 4). The rest do have a formal management plans; most of which were compiled or formalized in the 2000s. Many PAs also routinely revise and update plans, for example Kakadu (every 5 years) and Kings Park, which has had three different plans (1995-2013; 2013-2018; and 2018 onwards). Budgets for management of IAS are also highly variable, with some parks having no specific and very sporadic budgets (e.g. Channel Islands and Jasper Ridge), while other PAs have large annual budgets for control - those PAs with large and guaranteed budgets are most often the iconic national parks in Australia, South Africa and the USA (Table 5). Of the $75 \%$ of PAs with annual budgets, the range was huge and based on protected area size, the socio-economic characteristics of the country and other factors, with the lowest being 2500 US\$/annum (Campbell Islands), while Galápagos had the largest budget of 2.5 million US $\$$ /annum. In the USA and Australia PAs had average management budgets of 400,000 US\$/annum as compared to developing regions like South Africa and Indonesia which had average budgets of around 75,000 US\$/annum. Interestingly, large budgets do not necessarily always equate to more effective control; for example, Kings Park and Galápagos have substantial budgets for control but showed big increases in the numbers of listed invasive species. Similarly, some areas with small control budgets or no real management showed decreases or little change in the number of species listed and invasive species threats (Campbell island, Isle of Rum and Hluhluwe-iMfolozi), suggesting many other social-ecological factors may influence invasion rates, invasion threats and impacts and their management success in PAs globally.

3.1.3.2. Specific management trends for species mentioned in the $1980 \mathrm{~s}$ publications. We listed 201 species mentioned in the publications from the 1980s special issue (see Supplementary Material, File 2). Of these, we could find no further mention of 11 species and might be as a result of various factors. For example, Tilapia spp. Passer domesticus, Fringilla coelebs, Pavo cristatus, Sturnas vulgaris in Cape of Good Hope, Acacia mearnsii in Hluhluwe-iMfolozi, Mus musculus and R. rattus in Organ Pipe Cactus National Monument might have died out naturally before the next assessment or been misidentified, furthermore some species that were previously listed as invasive aliens are now considered as native (e.g. Cocos nucifera and Corvus albus in Aldabra, and Castor canadensis in Sequoia and Kings Canyon National Park). Of the 190 species listed in the 1980 s publications, only $39 \%$ were specifically managed in the past and/or are still being managed today, with mixed outcomes (Table 6). Despite management of these 70 listed species, $30 \%$ are considered to be increasing in extent and threat, while $41 \%$ are decreasing in threat, and $26 \%$ are considered as unchanged (Supplementary Material, File 2 ). Of those that are increasing or stable even with management, only $5 \%$ are vertebrates. For species listed in the 1980 s publications that are not managed, $6 \%$ are considered to be decreasing in extent due to natural causes (e.g. Cyprinus carpio in Kruger due to varying river

Table 6

A comparison of the change in managed vs. unmanaged species listed in the 1988 special issue.

\begin{tabular}{lcc}
\hline & Managed (39\%) & Unmanaged (71\%) \\
\hline Increasing & $30 \%$ & $26 \%$ \\
Decreasing & $41 \%$ & $6 \%$ \\
Stable & $26 \%$ & $56 \%$ \\
Unknown & $0 \%$ & $12 \%$ \\
\hline
\end{tabular}




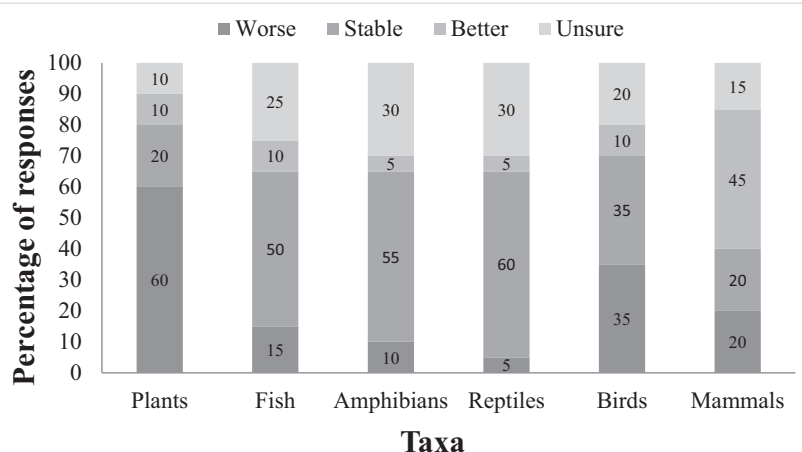

Fig. 3. Responses of managers and researchers regarding the perceived threat from different taxa now compared to the 1980s, for each protected area. The differences in perceived threats over time between taxonomic groups were significant (LH-ratio $=39.954, p<0.0001)$.

dynamics, $F$. catus on Campbell, Cinchona succirubra on the Galápagos and others), $26 \%$ are increasing, 56\% have stable populations, and for $12 \%$ of species it is unknown or data are deficient (Supplementary Material, File 2). Of the species not being managed and increasing, only $3 \%$ are vertebrates, the rest being plants. There have also been seven successful eradications/extirpation of specifically mentioned species since the 1980s (listed in Table 4 with a *).

\subsubsection{Overall threat perceived by managers and researches}

Overall, the perceived threat (a factor of species listed, impacts and management responses) of invasive species is increasing significantly for some taxa while it is stable for others (Fig. 3). The threat from plant invasions is perceived to have worsened in more than half of the PAs (60\%) since the 1980 s, while a third are seen to be facing increased threat from invasive birds (35\%). For other taxa (fish, amphibians and reptiles) the perceived threat is worse for between 5 and $20 \%$ of PAs and is overall considered as fairly stable. For only one group (mammals) the perception is that in $45 \%$ of PAs the current threat level has been significantly reduced since the 1980s, through effective management and many successful eradication programmes (see full case study descriptions in the Supplementary Material File 2).

\section{Discussion}

Long-term monitoring and assessment of trends over large temporal scales is commonly lacking in invasion science research, as in natural resource management and conservation programmes generally (Turner II et al., 2016). However, assessing long-term trends are very useful to provide insights for improving management (McGeoch et al., 2010), for policy development (Vaughan et al., 2001), monitoring change (Latombe et al., 2017), as well as for improving scientific understanding and for advancing knowledge. This study revisited PAs that were studied in the mid-1980s under the SCOPE programme and shows some broad-scale trends that offer valuable lessons.

Firstly, as tested in the 1980s, the realisation that PAs, as benchmarks of undisturbed 'natural' systems that would be resistant to invasions, was not true (Usher, 1988). Further evidence of increasing invasions in most PAs 30 years on reinforces this fact and highlights that even relatively undisturbed and biologically resilient and intact landscapes are vulnerable to biological invasions which are a major threat to their integrity. These PAs are often sentinel sites for biodiversity conservation and therefore need to be better protected from invasions and other threats.

A common finding in the 1980s was that evidence of ecology and the real effects of IAS within PAs was lacking, and that this lack of strong evidence made management and listing of invasive species problematic (Usher et al., 1998a). Despite some examples with very good understanding of specific genera (rats) in specific contexts (islands) (e.g. Harper and Bunbury, 2015), in general, this is still an issue today - with many PAs not specifically trying to understand ecology or measure impacts to guide policy and management of invasive species (Foxcroft et al., 2013a). In a global analysis of quantitative studies of alien plant impacts within and outside PAs, Hulme et al. (2014) showed that PAs are a significant focus for quantitative impact studies in invasion science, but that the biogeographic focus of research effort does not coincide with the global distribution of PAs. Moreover, only a minority of the studies assessed by Hulme et al. (2014) provide any subsequent management recommendations, which mirrors the suggestion by Foxcroft et al. (2013b) that there is a major lack of empirical evidence of the impacts of invasive species in PAs. An improved understanding of the mechanisms of impacts would help to justify the allocation of funding for control and help with prioritisation planning. Based on the limited evidence available, invasive species clearly can and do pose serious threats in PAs and where this has been studied, the understanding of impacts has been important for guiding management. For example, in the Cape of Good Hope, Xenopus laevis poses a major threat to the endemic $X$. gilli though hybridisation and predation on young tadpoles (Fogell et al., 2013). Evidence of this has guided management with subsequent benefits to populations of the endemic $X$. gilli (De Villiers et al., 2016). In Galápagos, the invasive tree Cinchona pubescens has, though competition and alteration of ecosystem functioning, decreased native species diversity by $50 \%$, having a strong negative effect on endemic species (Jäger et al., 2009). These invasions also facilitated secondary invasions of other species, which was important to recognise for management and post-removal restoration - to prevent invasion meltdowns (Green et al., 2011).

Although > 30 years have elapsed since the major threat IAS pose to PAs was highlighted (Usher et al., 1988), invasions appear to be worsening in many PAs, especially in the case of invasive plants. This holds true in most PAs, regardless of whether management plans are in place or of the social-ecological context in which the PA is situated (Figs. 2, 3). Invasive mammals are an exception, and major management successes have been achieved in about half of the PAs studied (Fig. 3 and Supplementary Material, File 2) which has led to considerable decreases in threat levels. Protected areas on islands have done particularly well in terms of managing invasive mammals (Table 4; Supplementary material File 2). This is probably due to the fact that most mammal invaders are easier to detect and control than plants or other taxa (Clout and Veitch, 2002) and the continuous spread or reintroduction into island PAs can be limited. Furthermore, rates of introduction for mammal species seem to be slowing at a faster rate globally than for other taxa (Seebens et al., 2017). Plants remain an issue as there are likely to be many more pathways and vectors for them into PAs (Foxcroft et al., 2019), and higher propagule pressure driving increased invasions and spread.

In many PAs the threat and number of IAS have increased over time. There are several probable reasons for this. Monitoring and understanding of invasions was not as good in the 1980s and negative impacts are better understood now. For example, in Buluran National Park in Indonesia where there were many unknowns in the 1980s publications, whereas full assessments were done recently and so with time knowledge has improved (Padmanaba et al., 2017). Another reason is that rates of introductions have increased over the last 30 years (Seebens et al., 2017). For example, Galápagos was much more isolated in the 1980s than it is now; human settlement on the island has grown and tourism has increased dramatically in the last few decades, leading to increased introductions (Table 1). Another reason is that some species that are now deemed a major threat were probably in a lag phase (Aikio et al., 2010) in the 1980s - for example Cotoneaster simonsii on the Isle of Rhum. There have probably also been introductions and rapid spread of transformer invasive species into PAs in the last 30 years, such as $P$. hysterophorus and $C$. odorata into the SerengetiNgorongoro (Witt et al., 2017). Furthermore, increasing threat levels 
may be due to be due to limited and/or ineffective management intervention in many PAs. Interestingly, although some PAs had fewer IAS listed in 2018 than in the 1980s, managers and researchers considered the threats posed by IAS to be higher now than in the past (Figs. 1 and 3). This might be due to the effects of a few very widespread transformers or potentially regime-shift causing species that have significant impacts and that are still as prominent now as they were in the 1980s (Gaertner et al., 2014; Shackleton et al., 2018). These high-impact transformer species are also likely to be the most difficult to manage, resulting in their threat remaining high. This is illustrated by the fact that $30 \%$ of species listed as a problem in the original SCOPE study (Table 6) are still increasing in extent and threat despite management efforts over three decades. Some examples are Pennisetum polystachyon in Kakadu, Acacia dealbata in Jasper, Mesembryanthemum crystallinum in Channel Islands, and F. catus in Galápagos. Lastly, perceptions are shaped by many factors and there is potential for bias due to how people view and consider invasions and their threats over time (Shackleton et al., 2019b).

There are several potential reasons for the decrease in invasive species being listed and perceived threats in many PAs. Firstly, greatly improved knowledge of invasive species globally (including advances in the terminology applied to different categories of non-native species) means that some taxa listed as "invasive" in the 1980s have probably been removed from this category, for various reasons (e.g. taxa incorrectly labelled as IAS but which are native "weedy" species, or species that more appropriate labelled as "alien" or "casual" species sensu Richardson et al., 2000) (see Supplementary Material, File 2). In some PAs, the lower number of alien species may be due to successful eradications, such as on Aldabra which is also isolated and has limited potential for reintroduction. In Cape of Good Hope, major transformer species such as Australia Acacia species are managed though biological control and although they are still present, their threats have decreased.

Although the threats of IAS are still increasing we draw on a few examples from management successes and failures from the case-study PAs which can help guide policy development and improve management in the future. Most PAs have attempted eradications/extirpations, and there have been many successes (Table 4) - but also many failures (see Supplementary Material, File 2). Many successful plant and mammal eradication campaigns were found, as well as successful eradication of birds and fish highlighting it is possible for a range of taxa. Many successful eradications have also been achieved in PAs on continental ecosystems which is encouraging for future management. Eradication attempts for invasive plant species on the Galápagos have provided important insights on this management approach (see Gardener et al., 2010; Gardener et al., 2013; Buddenhagen and Tye, 2015). In particular, PAs with people living in or very near to them are likely to face greater challenges (e.g. Spear et al., 2013) and have a lower likelihood of eradication compared with those with no people and/or are more isolated. Adequate and continued funding are obviously also crucial ingredients for success (Gardener et al., 2010) as is the effective use of available resources and good implementation of control techniques (Cheney et al., 2019). It is also important that feasibility studies are done to determine whether eradication attempts are appropriate. Acting early, having support from authorities and other key stakeholders is also crucial as seen in the case of Kruger, where many alien species were removed from tourist camps in a prioritised order (Foxcroft, 2001; Foxcroft et al., 2008). The successful eradications/extirpations we have highlighted have potentially reduced invasion debt (Essl et al., 2011; Rouget et al., 2016), and should be promoted further.

There has been much success in the management of well-established and high impact mammals (including many eradications of widespread species) in the PAs analysed in this article, suggesting there is good knowledge and evidence on how to do this (Figs. 2, 3 Supplementary material, File 2). Managing mammals should be promoted elsewhere as an easy option for overall impact reduction of biological invasion in
PAs. However, some small challenges arise when species are perceived as valuable (e.g. Bubalus bubalis in Kakadu) or highly charismatic (e.g. Hemitragus jemlahicus in Cape of Good Hope and the broader Table Mountain National Park and Equus caballus in Kakadu) (Robinson et al., 2005; Gaertner et al., 2016). Successful attempts in dealing with emerging or well-established plant invasions are less frequent; such invasions are very difficult and expensive to manage and the threat from such invasions continues to grow. Besides numerous cases using biological control (see below), a few other examples in case-study PAs used more traditional control approaches from which lessons can be learned. For example, in Haleakalā, Miconia calvescens, a species with well-known negative impacts, was discovered $8 \mathrm{~km}$ from the PA in 1988. A containment strategy was implemented relatively rapidly in 1991 with the support of local institutions to prevent the plant from entering the PA. This attempt has had long-term commitment and the species has not yet entered the PA but is present on its borders. Continuous efforts, collaboration between actors, and the sustained availability of funding (over US\$ 1 million/annum) are key elements of this success story (Meyer et al., 2011; Loope et al., 2013). In contrast, small populations of Hedychium gardnerianum were also discovered in Haleakalā in the mid-1980s. Control efforts were initiated less rapidly for this species; despite sustained effort and funding, this species continues to spread rapidly in the park. These examples and others point to the importance of prompt action to curb spread and/or incursion of known high-impact invasive species on the borders of PAs. For example, major invasive species like Chromolaena odorata, Opuntia stricta and Prosopis juliflora on the outskirts of Serengeti (Witt et al., 2017) and Rhinella maria which is close to and likely to become invasive in Kakadu (Kearney et al., 2008), and others (see Supplementary Material, File 2), can and should be contained before they enter PAs and cause impact. Acting early to prevent impacts arising within the PA, while costly, will in the long run be cheaper than allowing the species to invade a PA.

Widespread invasive species in PAs can also be controlled though innovative and sustained approaches. In Hluhluwe-iMfolozi the transformer species $C$. odorata that posed major threats to biodiversity in the area (Mgobozi et al., 2008; Dumalisile and Somers, 2017), has been well managed using adaptive approaches and good planning (see details in; te Beest et al., 2017). Sustained funding and long-term buy in are essential components for success. Management plans should be flexible, focus first on containment of threatening IAS, then aim to reduce the extent of invaded areas, with adequate monitoring as illustrated from the successful Hluhluwe-iMfolozi case (te Beest et al., 2017). Similarly, in developing nations it is often highly important to involve local communities to allow for benefit sharing (e.g. local employment) to ensure control (te Beest et al., 2017). Despite this success for $C$. odorata, recently there was a lull in management for two years in Hluhluwe-iMfolozi, (due to funding and safety issues, and other conservation pressures and priorities), and within two years it has been suggested that $C$. odorata has already reinvaded many areas that were cleared, but attempts to re-establish effective control are in place (B. van Wilgen: pers. comm.). This shows the need for sustained and committed control if management is going to be effective but also the huge challenges that are faced. With plants in particular, the removal of one widespread invasive species may facilitate the establishment of another species. For example, in the Galápagos good initial control of Rubus niveus resulted in secondary colonisation of other invasive species or recolonisation of $R$. niveus due to its persistent seedbanks (Gardner et al., 2013). Similar issues are faced in other PA, such as with Tamarix ramosissima in the USA (Reynolds and Cooper, 2011; Sherry et al., 2016). This suggests that there is the need for more research on active restoration after removal of invasive species in PAs (e.g. Ruwanza et al., 2013) to deal with legacy effects (Corbin and D'Antonio, 2012) and to prevent invasion meltdown scenarios (Essl et al., 2011).

A key observation from case studies in Australia, South Africa and the USA (Kruger, Cape of Good Hope, Channel Island, Kings Park, Kakadu and others) is that when classical biological control is 
successful, it provides a highly efficient mechanism to manage IASs especially in rural areas with large-scale invasions or in countries that lack the resources needed to sustain other forms of long-term management (Morin et al., 2006; Wenner et al., 2009; Moran and Hoffmann, 2012; Foxcroft et al., 2017a; Supplementary Material, File 2). This has been a particularly strong development in management since the 1980s and offers clear opportunities for dealing with major invasions within PAs in the future. For example, many high impact invasive waterweeds and $O$. stricta no longer need other forms of control in Kruger due to successful biological control (Foxcroft et al., 2017b, Supplementary Material, File 2). A number of other plant species have been successfully controlled using biological control in other case-study PAs too, for example Acacia species in the Cape of Good Hope (Moran and Hoffmann, 2012) and Tamarix ramosissima in PAs in the USA (Harms and Hiebert, 2006; DeLoach et al., 2007). Channel Islands have also successfully eradicated the invasive bee (Apis mellifera) using biological control (Wenner et al., 2009) (also see Supplementary Material, File 2 for more details). Another insect, Icerya purchasi, has been effectively controlled by the biological control agent Rodolia cardinalis in the Galápagos (Alvarez et al., 2012), suggesting this control approach can be used and successful for a range of taxa. In general, the benefit/cost ratio of using biological control agents for invasive species is high and exceeds any other management approach; this helps to ensure long-term sustainability and cost-effectiveness of control (Page and Lacey, 2006). We believe that more resources should be devoted to seeking biological control solutions for major plant invasions in PAs worldwide. This is despite the fact that biocontrol agents sometimes fail to establish (often due to climate factors or different varieties of the invasive species) or to induce measurable control effects on the invasive species. Unsuccessful or attempts with limited success in case study PAs include Salvinia adnata in Kakadu (Schooler et al., 2011), Senna pendula and Asparagus plumosus in Myall Lakes (see Supplementary Martial, File 2). Other challenges are that initial funding required for research on biological control is often substantial, with no guarantee of success, and that the capacity to do the work is lacking in some regions. Biological control research to find safe host-specific agents takes time, sometimes too long to curb the spread of emerging invasive species, as in the case of $M$. calvescens in Haleakalā (Loope et al., 2013).

Some further important changes in management approaches have been noted over the last 30 years. In the past, management focused mainly on the protection of endemic natives and reducing only IAS with large landscape-level effects (Usher et al., 1988). Management currently focusses on the entire invasion process and is often more integrative. For example, relatively recently biosecurity, preventative and anticipatory measures are being included in management plans for most PAs (Table 5). This might help to reduce introduction rates in the future, i.e., an assessment 30 years from now may reveal a slower rate of accumulation of invasive taxa (although evidence from Seebens et al. (2017) suggests otherwise). Introduction rates might particularly relate to how the PA is situated in the landscape and the number of pathways present (Pyšek et al., 2002; Hulme, 2009). Except for the Galápagos, islands appear more stable in relation to other areas, despite receiving less management attention (Tables 1 and 5). Evidence also suggests that PAs with high human populations nearby or in them (Spear et al., 2013), and those connected to rivers which are a primary pathway (Foxcroft et al., 2019) are particularly vulnerable to new invaders; this is crucial knowledge that can guide and improve the development of monitoring and eradication efforts. For example, Aldabra and Campbell Island have had relatively minor changes in invasion threat because they are so isolated and have good biosecurity. However, Galápagos, also an island with good biosecurity and a large management budget, has shown a major increase in invasion threat due a growing population and increase in tourism. On other had the Isle of Rum, which has a resident human population, has experienced little change over the last 30 years, suggesting other contextual factors might also come into play.
Many PAs (70\%) (Table 5) are increasingly implementing Early Detection Rapid Reponses Management (EDRR). Such measures were much less common in the past, although they have been in place for Haleakalā since the late 1980s (Loope et al., 2013) (Also see Supplementary Material, File 2). EDRR is promoted because acting quickly can be less costly than if the species is allowed to invade large areas (Vander Zanden et al., 2010). Most PAs practicing EDRR apply it to between one and three emerging invasive species, although Canyonlands and Arches, Kruger, and Kings Park are applying the approach for 10 or more species. This approach will help to prevent the rise of major impacts in the future.

Another newer trend is that many PAs are investing in knowledge and awareness programmes and working with neighbouring stakeholders to manage invasions. However, this was not unique to PAs as there was little awareness in the 1980s in general, and there is much scope for increasing engagement and collaboration with other actors and the public to aid with management (Foxcroft, 2001; Robinson et al., 2005; Vander Zanden et al., 2010; Novoa et al., 2018; Pagés et al., 2019; Shackleton et al., 2019c). This can range from awareness programmes aimed at changing behaviour to reduce the potential of introducing invasive species, to collaboration through citizen science, coordinated control and volunteering (Bryce et al., 2011; Pagés et al., 2019; Shackleton et al., 2019c).

A limitation of the assessments in the 1980s, and also this study, is that trends could not be assessed for all taxonomic groups. Insects and microorganisms were poorly covered in the 1980s reports, preventing any re-analysis now, and other taxa (freshwater invertebrates, marine species and others) were not assessed. This represents a gap in knowledge and reinforces the taxonomic bias in the field. Many of the taxa omitted in the analyses pose major threats to PAs and biodiversity globally (e.g. see Bax et al., 2003), also in our case study PAs (Wikelski et al., 2004). There is also a geographical bias in the original studies, with study sites concentrated in Australia, South Africa and the USA. Furthermore, the assessment of only 24 PAs in the 1980s and 21 now, results in limited opportunities for robust analyses which makes it difficult to draw clear conclusions. There is scope for further work to achieve better geographical and taxonomic coverage, larger sample sizes, and better data from more systematic sampling. This study reveals that most PAs are monitoring invasive species regularly and implementing and keeping records of control measures (Table 5). However, information relating to this is not coordinated and is difficult to access. One aspect that could help with research and management that is lacking currently is a freely accessible global database with key data on biological invasions in PAs. Drawing on established monitoring and reporting frameworks (e.g. Wilson et al., 2018), a standardised approach should be used for collating and storing data. This could help to work towards and meeting the vision for global monitoring of biological invasions (McGeoch et al., 2010; Latombe et al., 2017).

We conclude that invasive species still pose a major threat to PAs globally and that invasions remain a major issue for biodiversity conservation. However, our knowledge base has grown considerably over the last 30 years and continues to grow. This has allowed us to better understand invasion processes and to develop and refine new control techniques which has improved and will continue to improve overall management of invasive species in PAs. Some positive cases discussed here should be used to promote further interventions. Increasingly the policy and legislation addressing biological invasions and conservation, which were less common in the past, will help with this challenge moving forward. In the future monitoring and assessments of specific PAs should be better stored and shared as it will help management, policy and scientific understanding moving forward. In terms of practical control, we advocate for continued and increased uptake of biosecurity and rapid response measures as well as further prompting the use of biological control for well-established and wide-spread invasions. Increasingly adaptive and evidence based management strategies should be implemented. 


\section{Author statement}

The study was conceived and designed by DMR and RTS. All authors contributed to designing the final methodological approach and data collection template. RTS collected the data with help from LF, PP and DMR. RTS and LW wrote the first draft of the manuscript. RTS conducted the statistics and LW created the map. All authors contributed to editing and revising further drafts of the MS.

\section{Declaration of competing interest}

We declare that there are no conflicts of interest regarding this research and manuscript.

\section{Acknowledgements}

We thank the many managers and researchers who provided us with the data needed to produce this study. In particular we thank Arne Witt, John Richard Mbwambo, Lesley Watt, Michael Padmanaba, Titiek Setyawati, Jeanne Taylor, Herbert Morawe, Holger Kolberg, Ken Convery, Nona Chiariello, Heinke Jaeger, Nancy Bunbury, April Burt, Fiona Miller, Chad Cheney, Rijk Morawe, Peter Holm, Jeanne Taylor, Jo Hiscock, Holger Kolberg, Erik Frenzel, Mariska te Beest, Dave Bruce, Daniel, Ryan, Amelia Ryan, Paul Johnson, Liz Ballenger, Matthew Van Scoyoc, Jeffrey (Woody) Mallinson, who helped to provide us with data and information and many others who acted as intermediaries. There were also many others who helped along the way too and we thank everyone who provided help and advice to find the correct people to contribute the data collection. RTS and DMR were supported by the DSI-NRF Centre of Excellence for Invasion Biology and the National Research Foundation, South Africa (grant 85417). PP was supported by EXPRO grant no. 19-28807X (Czech Science Foundation) and long-term research development project RVO 67985939 (The Czech Academy of Sciences). LCF acknowledges support from South African National Parks, the DSI-NRF Centre of Excellence for Invasion Biology, Stellenbosch University and South African National Research Foundation.

\section{Appendix A. Supplementary data}

Supplementary data to this article can be found online at https:// doi.org/10.1016/j.biocon.2020.108424.

\section{References}

Aikio, S., Duncan, R.P., Hulme, P.E., 2010. Lag-phases in alien plant invasions: separating the facts from the artefacts. Oikos 119, 370-378.

Alvarez, C.C., Causton, C.E., Hoddle, M.S., Hoddle, C.D., van Driesche, R., Stanek, E.J., 2012. Monitoring the effects of Rodolia cardinalis on Icerya purchasi populations on the Galápagos Islands. BioControl 57, 167-179.

Bax, N., Williamson, A., Aguero, M., Gonzalez, E., Geeves, W., 2003. Marine invasive alien species: a threat to global biodiversity. Mar. Policy 27, 313-323.

te Beest, M., Howison, O., Howison, R.A., Dew, L.A., Poswa, M.M., Dumalisile, L., Janse van Rensburg, S., Ter Blanche, C., 2017. Successful Control of the Invasive Shrub Chromolaena odorata in Hluhluwe-iMfolozi Park. Conserving Africa's Mega-Diversity in the Anthropocene: The Hluhluwe-iMfolozi Park Story. Cambridge University Press, pp. 358.

Blackburn, T.M., Cassey, P., Duncan, R.P., Evans, K.L., Gaston, K.J., 2004. Avian extinctions and mammalian introductions on oceanic islands. Science 305, 1955-1958.

Brockie, R.E., Loope, L.L., Usher, M.B., Hamann, O., 1988. Biological invasions of island nature reserves. Biol. Conserv. 44, 9-36.

Bryce, R., Oliver, M.K., Davies, L., Gray, H., Urquhart, J., Lambin, X., 2011. Turning back the tide of American mink invasion at an unprecedented scale through community participation and adaptive management. Biol. Conserv. 144, 575-583.

Buddenhagen, C.E., Tye, A., 2015. Lessons from successful plant eradications in Galápagos: commitment is crucial. Biol. Invasions 17, 2893-2912.

Butchart, et al., 2010. Global biodiversity: indicators of recent declines. Science 328, 1164-1168.

Cheney, C., Esler, K.J., Foxcroft, L.C., van Wilgen, N.J., 2019. Scenarios for the management of invasive Acacia species in a protected area: implications of clearing efficacy. J. Environ. Manag. 238, 274-282.

Clavero, M., García-Berthou, E., 2005. Invasive species are a leading cause of animal extinctions. Trends in Ecology and Evolution 20, 110.

Clout, M.N., Veitch, C.R., 2002. Turning the Tide of Biological Invasion: The Potential for Eradicating Invasive Species. Turning the Tide: The Eradication of Invasive Species. IUCN SSC Invasive Species Specialist Group, Gland, Switzerland and Cambridge.

Conroy, M.J., Runge, M.C., Nichols, J.D., Stodola, K.W., Cooper, R.J., 2011. Conservation in the face of climate change: the roles of alternative models, monitoring and adaptation in confronting and reducing uncertainty. Biol. Conserv. 144, 1204-1213.

Corbin, J.D., D'Antonio, C.M., 2012. Gone but not forgotten? Invasive plants' legacies on community and ecosystem properties. Invasive Plant Science and Management 5, 117-124.

De Villiers, F.A., de Kock, M., Measey, G.J., 2016. Controlling the African clawed frog Xenopus laevis to conserve the Cape platanna Xenopus gilli in South Africa. Conservation Evidence 13, 17.

DeLoach, C.J., Moran, P.J., Knutson, A.E., Thompson, D.C., Carruthers, R.I., Michels, J., Herr, J.C., Muegge, M., Eberts, D., Randal, C., Everitt, J., 2007. Beginning success of biological control of saltcedars (Tamarix spp.) in the southwestern USA. In: XII International Symposium on Biological Control of Weeds. France, La Grande Motte, pp. 22-27.

Downey, P.O., Richardson, D.M., 2016. Alien plant invasions and native plant extinctions: a six-threshold framework. AoB PLANTS plw047.

Dumalisile, L., Somers, M.J., 2017. The effects of an invasive alien plant (Chromolaena odorata) on large African mammals. Nature Conservation Research: Zapovednaâ Nauka 2, 102-108.

Essl, F., Dullinger, S., Rabitsch, W., Hulme, P.E., Hülber, K., Jarošík, V., Kleinbauer, I., Krausmann, F., Kühn, I., Nentwig, W., Vilà, M., 2011. Socioeconomic legacy yields an invasion debt. Proc. Natl. Acad. Sci. 108, 203-207.

Fogell, D.J., Tolley, K.A., Measey, G.J., 2013. Mind the gaps: investigating the cause of the current range disjunction in the Cape Platanna, Xenopus gilli (Anura: Pipidae). PeerJ e166.

Foxcroft, L.C., 2001. A case study of human dimensions in invasion and control of alien plants in the personnel villages of Kruger National Park. In: McNeely, J.A. (Ed.), The Great Reshuffling: Human Dimensions of Invasive Alien Species. IUCN, Gland, and Cambridge, pp. 127-134.

Foxcroft, L.C., Richardson, D.M., Wilson, J.R., 2008. Ornamental plants as invasive aliens: problems and solutions in Kruger National Park, South Africa. Environ. Manag. 41, 32-51.

Foxcroft, L.C., Pyšek, P., Richardson, D.M., Genovesi, P., 2013a. Plant invasions in protected areas: outlining the issues and creating the links. In: Foxcroft, L.C., Pyšek, P., Richardson, D.M., Genovesi, P. (Eds.), Plant Invasions in Protected Areas: Patterns, Problems and Challenges. Springer, Dordrecht, pp. 19-41.

Foxcroft, L.C., Pyšek, P., Richardson, D.M., Pergl, J., Hulme, P.E., 2013b. The bottom line: impacts of alien plant invasions in protected areas. In: Foxcroft, L.C., Pyšek, P., Richardson, D.M., Genovesi, P. (Eds.), Plant Invasions in Protected Areas: Patterns, Problems and Challenges. Springer, Dordrecht, pp. 19-41.

Foxcroft, L.C., Pyšek, P., Richardson, D.M., Genovesi, P., MacFadyen, S., 2017a. Plant invasion science in protected areas: progress and priorities. Biol. Invasions 19, 1353-1378.

Foxcroft, L.C., van Wilgen, N.J., Baard, J.A., Cole, N.S., 2017b. Biological invasions in South African National Parks. Bothalia - African Biodiversity and Conservation 47, $1-12$.

Foxcroft, L.C., Spear, D., van Wilgen, N.J., McGeoch, M.A., 2019. Assessing the association between pathways of alien plant invaders and their impacts in protected areas. NeoBiota $43,1$.

Gaertner, M., Biggs, R., te Beest, M., Hui, C., Molofsky, J., Richardson, D.M., 2014. Invasive plants as drivers of regime shifts: identifying high priority invaders that alter feedback relationships. Divers. Distrib. 20, 733-744.

Gaertner, M., Larson, B.M., Irlich, U.M., Holmes, P.M., Stafford, L., van Wilgen, B.W., Richardson, D.M., 2016. Managing invasive species in cities: a framework from Cape Town, South Africa. Landsc. Urban Plan. 151, 1-9.

Gardener, M.R., Atkinson, R., Rentería, J.L., 2010. Eradications and people: lessons from the plant eradication program in Galápagos. Restor. Ecol. 18, 20-29.

Gardener, M.R., Trueman, M., Buddenhagen, C., Heleno, R., Jäger, H., Atkinson, R., Tye, A., 2013. A pragmatic approach to the management of plant invasions in Galápagos. In: Foxcroft, L.C., Pyšek, P., Richardson, D.M., Genovesi, P. (Eds.), Plant Invasions in Protected Areas: Patterns, Problems and Challenges. Springer Netherlands, Dordrecht, pp. 349-374.

Green, P.T., O'Dowd, D.J., Abbott, K.L., Jeffery, M., Retallick, K., Mac Nally, R., 2011 Invasional meltdown: invader-invader mutualism facilitates a secondary invasion. Ecology 92, 1758-1768.

Harms, R.S., Hiebert, R.D., 2006. Vegetation response following invasive tamarisk (Tamarix spp.) removal and implications for riparian restoration. Restor. Ecol. 14 $461-472$.

Harper, G.A., Bunbury, N., 2015. Invasive rats on tropical islands: their population biology and impacts on native species. Global Ecology and Conservation 3, 607-627.

Hejda, M., Pyšek, P., Jarošík, V., 2009. Impact of invasive plants on the species richness, diversity and composition of invaded communities. J. Ecol. 97, 393-403.

Hulme, P.E., 2009. Trade, transport and trouble: managing invasive species pathways in an era of globalization. J. Appl. Ecol. 46, 10-18.

Hulme, P.E., Pyšek, P., Pergl, J., Jarošík, V., Schaffner, U., Vilà, M., 2014. Greater focus needed on plant invasion impacts in protected areas. Conserv. Lett. 7, 459-466.

Huxel, G.R., 1999. Rapid displacement of native species by invasive species: effects of hybridisation. Biol. Conserv. 89, 143-152.

Jäger, H., Kowarik, I., Tye, A., 2009. Destruction without extinction: long-term impacts of an invasive tree species on Galápagos highland vegetation. J. Ecol. 97, 1252-1263.

Kearney, M., Phillips, B.L., Tracy, C.R., Christian, K.A., Betts, G., Porter, W.P., 2008. Modelling species distributions without using species distributions: the cane toad in 
Australia under current and future climates. Ecography 31, 423-434.

Latombe, G., et al., 2017. A vision for global monitoring of biological invasions. Biol. Conserv. 213, 295-308.

Loope, L.L., Sanchez, P.G., Tarr, P.W., Loope, W.L., Anderson, R.L., 1989. Biological invasion of arid land nature reserves. Biol. Conserv. 44, 95-118.

Loope, L.L., Hughes, R.F., Meyer, J., 2013. Plant invasions in protected areas of tropical Pacific Islands, with special reference to Hawaii. In: Foxcroft, L.C., Pyšek, P., Richardson, D.M., Genovesi, P. (Eds.), Plant Invasions in Protected Areas: Patterns, Problems and Challenges. Springer, Netherlands, Dordrecht, pp. 313-348.

Macdonald, I.A.W., Frame, G.W., 1988. The invasion of introduced species into nature reserves in tropical savannas and dry woodlands. Biol. Conserv. 44, 67-93.

Macdonald, I.A.W., Garber, D.M., DeBenedetti, S., Groves, R.H., Fuentes, E.R., 1988. Introduced species in nature reserves in Mediterranean climatic regions of the world. Biol. Conserv. 44, 37-66.

Mačić, V., et al., 2018. Biological invasions in conservation planning: a global systematic review. Front. Mar. Sci. 5, 178.

McGeoch, M.A., Butchart, S.H., Spear, D., Marais, E., Kleynhans, E.J., Symes, A., Chanson, J., Hoffmann, M., 2010. Global indicators of biological invasion: species numbers, biodiversity impact and policy responses. Divers. Distrib. 16, 95-108.

Meyer, J., Loope, L., Goarant, A., 2011. Strategy to control the invasive alien tree Miconia calvescens in Pacific islands: eradication, containment or something else? In: Veitch, C.R., Clout, M.N., Towns, D.R. (Eds.), Island Invasives: Eradication and Management. IUCN, Gland, pp. 91-96.

Mgobozi, M.P., Somers, M.J., Dippenaar-Schoeman, A.S., 2008. Spider responses to alien plant invasion: the effect of short-and long-term Chromolaena odorata invasion and management. J. Appl. Ecol. 45, 1189-1197.

Mooney, H.A., Mack, R.N., McNeely, J.A., Neville, L.E., Schei, P.J., Waage, J.K. (Eds.), 2005. Invasive Alien Species: A New Synthesis. Island Press, London SCOPE 63.

Moran, V.C., Hoffmann, J.H., 2012. Conservation of the fynbos biome in the Cape Floral Region: the role of biological control in the management of invasive alien trees. BioControl 57, 139-149.

Morin, L., Neave, M., Batchelor, K., Reid, A., 2006. Biological control: a promising tool for managing bridal creeper, Asparagus asparagoides (L.) Druce, in Australia. Plant Protection Quarterly 21, 69-77.

Novoa, A., et al., 2018. A framework for engaging stakeholders on the management of alien species. J. Environ. Manag. 205, 286-297.

Padmanaba, M., Tomlinson, K.W., Hughes, A.C., Corlett, R.T., 2017. Alien plant invasions of protected areas in Java, Indonesia. Sci. Rep. 7, 9334.

Page, A.R., Lacey, K.L., 2006. Economic impact assessment of Australia weed biological control. CRC for Australian Weed Management, Australia.

Pagés, M., Fischer, A., van der Wal, R., Lambin, X., 2019. Empowering communities or "cheap labour"? Engaging volunteers in the rationalised management of invasive laine species in Great Britain. J. Environ. Manag. 229, 102-111.

Pejchar, L., Mooney, H.A., 2009. Invasive species, ecosystem services and human wellbeing. Trends Ecol. Evol. 24, 497-504.

Pyšek, P., Jarošík, V., Kučera, T., 2002. Patterns of invasion in temperate nature reserves. Biol. Conserv. 104, 13-24.

Pyšek, P., Blackburn, T.M., García-Berthou, E., Perglová, I., Rabitsch, W., 2017. Displacement and local extinction of native and endemic species. In: Vilà, M., Hulme, P.E. (Eds.), Impact of Biological Invasions on Ecosystem Services. Springer, Berlin, pp. 157-175.

Reynolds, L.V., Cooper, D.J., 2011. Ecosystem response to removal of exotic riparian shrubs and a transition to upland vegetation. Plant Ecol. 212, 1243-1261.

Richardson, D.M. (Ed.), 2011. Fifty Years of Invasion Ecology: The Legacy of Charles Elton. Wiley-Blackwell, Chichester, UK.

Richardson, D.M., Pyšek, P., Rejmánek, M., Barbour, M.G., Panetta, F.D., West, C.J., 2000. Naturalization and invasion of alien plants: concepts and definitions. Divers. Distrib. 6, 93-107.

Robinson, C.J., Smyth, D., Whitehead, P.J., 2005. Bush tucker, bush pets, and bush threats: cooperative management of feral animals in Australia's Kakadu National Park. Conserv. Biol. 19, 1385-1391.
Rouget, M., Robertson, M.P., Wilson, J.R., Hui, C., Essl, F., Renteria, J.L., Richardson, D.M., 2016. Invasion debt-quantifying future biological invasions. Divers. Distrib. 22, 445-456.

Ruwanza, S., Gaertner, M., Esler, K.J., Richardson, D.M., 2013. The effectiveness of active and passive restoration on recovery of indigenous vegetation in riparian zones in the Western Cape, South Africa: a preliminary assessment. S. Afr. J. Bot. 88, 132-141.

Schooler, S.S., Salau, B., Julien, M.H., Ives, A.R., 2011. Alternative stable states explain unpredictable biological control of Salvinia molesta in Kakadu. Nature 470, 86.

Seebens, H., Blackburn, T.M., Dyer, E.E., Genovesi, P., Hulme, P.E., Jeschke, J.M., Pagad, S., Pyšek, P., Winter, M., Arianoutsou, M., Bacher, S., et al., 2017. No saturation in the accumulation of alien species worldwide. Nat. Commun. 8, 14435.

Shackleton, R.T., Biggs, R., Richardson, D.M., Larson, B.M., 2018. Social-ecological drivers and impacts of invasion-related regime shifts: consequences for ecosystem services and human wellbeing. Environ. Sci. Pol. 89, 300-314.

Shackleton, R.T., Shackleton, C.M., Kull, C.A., 2019a. The role of invasive alien species in shaping local livelihoods and human well-being. J. Environ. Manag. 229, 145-157.

Shackleton, R.T., et al., 2019b. Explaining people's perceptions of invasive alien species: a conceptual framework. J. Environ. Manag. 229, 10-26.

Shackleton, R.T., Adriaens, T., Brundu, G., Dehnen-Schmutz, K., Estévez, R.A., Fried, J., Larson, B.M., Liu, S., Marchante, E., Marchante, H., Moshobane, M.C., Novoa, A., Reed, M., Richardson, D.M., 2019c. Stakeholder engagement in the study and management of invasive alien species. J. Environ. Manag. 229, 88-101.

Sherry, R.A., Shafroth, P.B., Belnap, J., Ostoja, S., Reed, S.C., 2016. Germination and growth of native and invasive plants on soil associated with biological control of tamarisk (Tamarix spp.). Invasive Plant Science and Management 9, 290-307.

Simberloff, D., 2011. Charles Elton: Neither founder nor siren, but prophet. In: Richardson, D.M. (Ed.), Fifty Years of Invasion Ecology: The Legacy of Charles Elton. Wiley-Blackwell, Chichester, UK, pp. 11-24.

Spear, D., Foxcroft, L.C., Bezuidenhout, H., McGeoch, M.A., 2013. Human population density explains alien species richness in protected areas. Biol. Conserv. 159, 137-147.

Turner II, B.L., et al., 2016. Socio-Environmental Systems (SES) research: what have we learned and how can we use this information in future research programs. Curr. Opin. Environ. Sustain. 19, 160-168.

Usher, M.B., 1988. Biological invasion of nature reserves: a search for generalisations. Biol. Conserv. 44, 119-135.

Usher, M.B., Kruger, F.J., Macdonald, I.A.W., Loope, L.L., Brockie, R.E., 1988. The ecology of biological invasions into nature reserves: an introduction. Biol. Conserv. 44, 1-8.

Vander Zanden, M.J., Hansen, G.J., Higgins, S.N., Kornis, M.S., 2010. A pound of prevention, plus a pound of cure: early detection and eradication of invasive species in the Laurentian Great Lakes. J. Great Lakes Res. 36, 199-205.

Vaughan, H., Brydges, T., Fenech, A., Lumb, A., 2001. Monitoring long-term ecological changes through the ecological monitoring and assessment network: science-based and policy relevant. Environ. Monit. Assess. 67, 3-28.

Vilà, M., Hulme, P.E., 2017. Impact of Biological Invasions on Ecosystem Services. 12 Springer, Cham.

Vilà, M., Weiner, J., 2004. Are invasive plant species better competitors than native plant species? - evidence from pair-wise experiments. Oikos 105, 229-238.

Wenner, A.M., Thorp, R.W., Barthell, J.F., 2009. Biological control and eradication of feral honey bee colonies on Santa Cruz Island, California: a summary. In: Proceedings of the 7th California Islands Symposium, pp. 327-335.

Wikelski, M., Foufopoulos, J., Vargas, H., Snell, H., 2004. Galápagos birds and diseases: invasive pathogens as threats for island species. Ecol. Soc. 9.

Wilson, J.R.U., Faulkner, K.T., Rahlao, S.J., Richardson, D.M., Zengeya, T.A., van Wilgen, B.W., 2018. Indicators for monitoring biological invasions at a national level. J. Appl. Ecol. 55, 2612-2620.

Witt, A.B., Kiambi, S., Beale, T., van Wilgen, B.W., 2017. A preliminary assessment of the extent and potential impacts of alien plant invasions in the Serengeti-Mara ecosystem, East Africa. Koedoe 59, a1426. https://doi.org/10.4102/koedoe.v59i1.1426. 